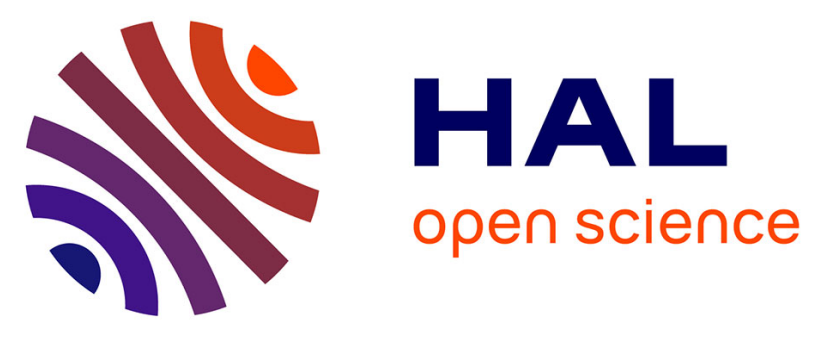

\title{
Study of DIC hydrothermal treatment effect on rheological properties of standard maize (SMS), waxy maize (WMS), wheat (WTS) and potato (PTS) starches
}

Zoulikha Maache-Rezzoug, Ikbal Zarguili, Catherine Loisel, Jean-Louis Doublier

\section{To cite this version:}

Zoulikha Maache-Rezzoug, Ikbal Zarguili, Catherine Loisel, Jean-Louis Doublier. Study of DIC hydrothermal treatment effect on rheological properties of standard maize (SMS), waxy maize (WMS), wheat (WTS) and potato (PTS) starches. Journal of Food Engineering, 2009, Article in Press (Article in Press), pp.Article in Press. 10.1016/j.jfoodeng.2009.06.052 . hal-00413220

\section{HAL Id: hal-00413220 \\ https://hal.science/hal-00413220}

Submitted on 4 Sep 2009

HAL is a multi-disciplinary open access archive for the deposit and dissemination of scientific research documents, whether they are published or not. The documents may come from teaching and research institutions in France or abroad, or from public or private research centers.
L'archive ouverte pluridisciplinaire HAL, est destinée au dépôt et à la diffusion de documents scientifiques de niveau recherche, publiés ou non, émanant des établissements d'enseignement et de recherche français ou étrangers, des laboratoires publics ou privés. 


\section{STUDY OF DIC HYDROTHERMAL TREATMENT EFFECT ON RHEOLOGICAL}

PROPERTIES OF STANDARD MAIZE (SMS), WAXY MAIZE (WMS), WHEAT (WTS)

AND POTATO (PTS) STARCHES

Z. Maache-Rezzoug ${ }^{\mathrm{a}^{*}}$, I. Zarguili $^{\mathrm{a}}$, C. Loisel $^{\mathrm{b}}, \mathrm{J}-$ L. Doublier, ${ }^{\mathrm{c}}$

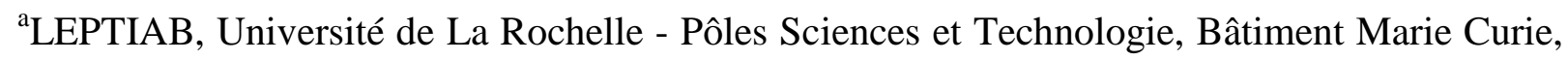
Avenue Michel Crépeau, 17042 La Rochelle, France.

${ }^{\text {b} L a b o r a t o i r e ~ G E P E A, ~ E N I T I A A ~ r u e ~ d e ~ l a ~ G e ́ r a u d i e ̀ r e, ~ B P ~ 82225, ~} 44322$ Nantes Cedex 3, France.

${ }^{c}$ UR1268 Biopolymères Interactions Assemblages, INRA, F-44300 Nantes.

Keywords: Starch, DIC hydrothermal treatment, Granulometry, Rheological properties.

*Corresponding author: Tél : (33) 05464586 15; Fax : (33) 0546458616

E-mail address: zrezzoug@univ-lr.fr 


\section{1. Abstract}

2 Standard maize (SMS), waxy maize (WMS), wheat (WTS) and potato (PTS) starches were

3 hydrothermally treated by Instantaneous Controlled Pressure Drop (DIC) process at different

4 pressure levels (1, 2 and 3 bar) corresponding to the temperatures of 100,122 and $136^{\circ} \mathrm{C}$,

5 respectively. The rheological properties and particle size of treated starches under various

6 conditions were compared to the native ones. The results showed for all starches, except for

7 WTS, a reduction of the consistency coefficient and the yield stress $\left(\tau_{\mathrm{o}}\right)$ with increased

8 intensity of the hydrothermal treatment conditions. Furthermore, $\tau_{\mathrm{o}}$ vanished for severe

9 treatment conditions. The DIC treatment yielded an increased fluidity and a loss of the

10 conservative modulus of the pastes, as a result of partial gelatinization of starch granules. The

11 extent of the observed effect depended on the botanical origin. Wheat starch exhibited a

12 different behaviour: the consistency coefficient and the conservative modulus being higher for

13 DIC treated starch except for the most severe conditions. 


\section{2. Introduction}

15 Starch has many applications in food and non-food industries. As an ingredient, it is extracted from only a few species such as maize, wheat, potato, rice, tapioca, and sago. Pregelatinized starches have been widely used for many foods as a major ingredient to provide thickened textures at temperatures below the gelatinization temperature. They are obtained from native or modified starch, by drum drying (Vallous et al., 2002) or by extrusion cooking (Barron et al., 2000). Other processes of physical modification have been explored to improve qualities of the starch such as annealing (Tester et al., 2000; Jayakody and Hoover, 2008) and heat moisture treatment (HMT) (Kulp and Lorenz, 1981; Hoover and Manuel, 1996; Jacobs, et al., 1998;

Collado and Corke, 1999; Tester et al., 2000; Gunaratne and Hoover, 2002; Vermeylen et al., 2006; Tukomane et al., 2007; Gunaratne and Corke, 2007, Chung et al., 2009). These two latter treatments differ in the water content, temperature and processing time used. Annealing occurs under large excess of water (50 to $60 \%$ ) and relatively low temperatures (below the gelatinization temperature), while the HMT is conducted under restricted moisture content (10$30 \%)$ and higher temperatures $\left(90-120^{\circ} \mathrm{C}\right)$. Both treatments are applied over large periods of time (10-16h). The main effects of HMT are loss of birefringence, increased gelatinization temperature, broadened or unchanged gelatinization temperature range, change in X-ray diffraction patterns, reduced swelling volume and solubility, with consequent changes in functionality (Donovan et al., 1983; Collado and Corke, 1999; Gunaratne and Hoover, 2002). Annealing results in improved perfection of the crystallites within starch granules that narrows the gelatinization temperature interval; consequently, gelatinization temperatures shifted towards higher values (Hublin, 1994; Jacobs et al., 1998; Tester et al., 2000). The enthalpy of gelatinization remains unchanged or is moderately increased depending upon annealing conditions (moisture content and time) and the botanic origin (Karlsson and Eliasson, 2003; 
of starch granules is modified by these two usual physical treatments without disrupting the

40 integrity of granule (Lim et al., 2001).

HMT starches have generally been performed at the laboratory scale and many authors have reported that such conditions produce inhomogeneous samples with lumps of gelatinized starch

43 beside heat-moisture treated starch. For this reason, pressure is often required to ensure sufficient heating. To obtain a uniform heat distribution and rapid penetration of steam into the starch granules, Maruta et al. (1994) improved the conventional method by creating a reduced pressure in the vessel before the injection of live steam. This method was designated by these authors as the reduced-pressurized heat moisture treatment (RP-HMT).

The DIC treatment (Instantaneous Controlled Pressure Drop) has been developed at the laboratory as well as the pilot scale (Rezzoug et al., 2000), for drying and texturizing of food products such as pasta products (Maache-Rezzoug and Allaf, 2005). As for the RP-HMT process, an initial vacuum is applied before the treatment which is performed under high temperature/high steam pressure; the hydro-treatment step is then followed by an abrupt pressure drop towards vacuum pressure contrary to the RP-HMT treatment. This step induces a rapid modification of the thermodynamic equilibrium reached during the pressurisation $\left(\mathrm{P}_{1}, \mathrm{~T}_{1}\right)$ towards another equilibrium state $\left(\mathrm{P}_{2}, \mathrm{~T}_{2}\right)$. This new state induces a rapid cooling and the resulting temperature value depends on the vacuum pressure level (Zarguilli et al., 2009). The originality of the DIC process compared to other hydrothermal treatments is that starch is treated at an initial moisture content of $12.5 \%$ (wet basis), no hydration step being then used. During the treatment, the heating of starch is obtained by the absorption of latent heat of steam condensation which causes an increase in the moisture content as the processing time and pressure level increase (Zarguili et al., 2009).

The major effects observed after DIC treatment are almost similar to HMT treatment except that the gelatinization temperature range is narrowed as observed with annealing (Hublin, 1994; 
Jayakody and Hoover, 2008). This result suggests that the treatment firstly induced the melting of crystallites of low cohesion (low stability) which required less energy to melt. Consequently, the residual structure after the DIC treatment contained crystallites with a greater stability (cohesion) (Maache-Rezzoug et al., 2008). Preliminary studies on standard and waxy maize starches (Loisel et al., 2006, Zarguili et al., 2006) showed that the thermal properties of DIC treated starch depend on the processing time and the steam pressure level. Increasing these two parameters induces an increase in the onset $\left(\mathrm{T}_{\text {onset }}\right)$ and in the peak $\left(\mathrm{T}_{\text {peak, }}\right)$ temperatures of gelatinization and a reduction in gelatinization enthalpy. The occurrence of a partial or total gelatinization was clearly attested by the decrease of enthalpy and a loss of birefringence under polarized light. The X-ray diffraction pattern confirmed the partial or total loss of the crystalline structure of native starch depending on the conditions of the DIC treatment: the relative crystallinity of hydrothermally treated maize starch decreased and the polymorphic type changed. The A-type crystalline pattern was progressively lost with the increase of processing pressure ( $\geq 2$ bar), and was substituted by the $\mathrm{V}_{\mathrm{h}}$-type $\mathrm{X}$-ray diffraction pattern, corresponding to the formation of amylose-lipid complexes. At severe DIC conditions (pressure level of 3 bar), the typical peaks of A-type X-ray diffraction pattern were substituted completely by the ones of the $\mathrm{V}_{\mathrm{h}}$-type pattern (Maache-Rezzoug et al., 2008).

The objective of the present study was to describe the rheological properties of hydrothermally treated starches in the DIC process in relation to starch granules properties (size and size distribution, swelling behaviour). This study was based on rheological measurements (viscosity and viscoelasticity). These effects were investigated on starches of different origins: standard maize (SMS), waxy maize (WMS), wheat (WTS) and potato (PTS); identical treatments conditions (processing pressure and time) were applied, except for PTS. Lower pressure/time conditions were applied to potato starch due to its higher sensitivity to hydrothermal treatment. 


\section{3. Materials and methods}

89

90

91

92

93

94

95

96

97

98

99

100

101

102

103

104

105

106

107

108

109

\subsection{Materials}

Standard maize starch (SMS), waxy maize starch (WMS, Waxilys 200), wheat starch (WTS) and potato starch (PTS) were supplied by Roquette Frères (Lestrem, France). The moisture content of these starches during the treatment was about $12 \%$ wet basis.

\subsection{Methods}

\subsubsection{Moisture content}

The starch moisture content was determined by air oven at $105^{\circ} \mathrm{C}$ during $24 \mathrm{~h}$, according to the A.F.N.O.R (NF V03-707, 2000) standard method and related to the wet basis (\%, wb).

\subsubsection{DIC hydrothermal treatment}

The equipment and procedure of DIC hydrothermal treatment were largely described in previous studies (Zarguili et al., 2006). During the treatment, $22 \mathrm{~g}$ of $\operatorname{starch}(12.5 \%$, wet basis) disposed in circular containers were placed in the processing vessel $(12 \mathrm{~L})$ in a layer of $20 \mathrm{~cm}$ diameter and $0.5 \mathrm{~cm}$ height. An initial vacuum of $50 \mathrm{mbar}$ was established. As demonstrated by Zarguili (2006), this initial vacuum allows the air resistance to be reduced and thus facilitates the diffusion of steam into the product, consequently a rapid heating is obtained. Saturated steam is introduced into the vessel at a fixed pressure level (1 to 3 bars) and maintained during a determined processing time. In this study the processing pressure was fixed at $1 \mathrm{bar}\left(100^{\circ} \mathrm{C}\right)$, 2 bar $\left(122{ }^{\circ} \mathrm{C}\right)$ and 3 bar $\left(135^{\circ} \mathrm{C}\right)$. The pressurisation is followed by an abrupt decompression towards vacuum (50 mbar). After the vacuum phase, atmospheric air is injected to return to atmospheric pressure for sample recovery. During the treatment, starch is heated by the absorption of latent heat of vapour condensation and its moisture content is increased. 


\subsubsection{Pasting procedure using the Brabender Viscograph}

111 The DIC treated starches were pasted with demineralised water using a Brabender Viscograph

112 in order to obtain starch pastes under repeatable conditions. The starch concentrations were

113 chosen to lie within the sensitivity range of the Viscograph, depending on the botanical origin

114 of starches. The concentrations used were $6 \%, 4 \%, 7 \%$ and $2 \%$ for SMS, WMS, WTS and PTS,

115 respectively. The suspension was heated at $1.5^{\circ} \mathrm{C} / \mathrm{min}$ from 50 to $95^{\circ} \mathrm{C}$, then kept for $20 \mathrm{~min}$

116 at the plateau temperature and subsequently cooled down to $70{ }^{\circ} \mathrm{C}$ at $1.5{ }^{\circ} \mathrm{C} / \mathrm{min}$ before

117 immediate characterisation. The starch concentration was checked by drying the suspensions as

118 previously described (3.2.1.).

\section{3.2.4. Granule size distribution}

120 Granule size determination was carried out at room temperature using a Malvern Master Sizer

121 (Malvern Instruments, Ltd) laser scattering analyser with a $300 \mathrm{~mm}$ Fourier cell (range 0.05-

$122879 \mu \mathrm{m})$. The starch dispersion was first diluted (1/10) with demineralised water at $20^{\circ} \mathrm{C}$ before

123 and immediately after the pasting procedure in the Brabender Viscograph, and then dispersed

124 into the sample dispersion unit $(1 \mathrm{ml} / 100 \mathrm{ml}$ water $)$. The measure was repeated three times. The 125 volume distribution was obtained according to the Mie scattering theory (Loisel et al., 2006).

126 From each distribution, the median volume diameter $\left(D_{v}, 0.5\right)$ was presented and the swelling

127 ratio was defined as $\left(\mathrm{D} / \mathrm{D}_{0}\right)^{3}$, with $\mathrm{D}$ and $\mathrm{D}_{0}$ the median diameters of treated and native starch,

128 respectively (Nayouf et al., 2003); the size distribution was evaluated using the dispersion

129 index referred to as the span, by the following equation:

$130 \quad \operatorname{Span}=\frac{D(v, 0.9)-D(v, 0.1)}{D(v, 0.5)}$ 


\subsubsection{Rheological properties}

132 Flow behaviour and viscoelastic properties of starch pastes were measured at $60{ }^{\circ} \mathrm{C}$ (to avoid 133 retrogradation) using a controlled stress rheometer (TA Instrument AR1000) with the 134 cone/plate geometry $\left(6 \mathrm{~cm} / 2^{\circ}\right)$. The starch dispersions at $60{ }^{\circ} \mathrm{C}$ were poured onto the preheated 135 plate of the rheometer, and then covered by a thin layer of paraffin oil on the edge of the 136 sample to avoid evaporation. For flow measurements, an up-down shear scan from 0 to $660 \mathrm{~s}^{-}$

$137{ }^{1}$ (4 min) was linearly applied, followed by a logarithmic stepwise decrease from 660 to $0.01 \mathrm{~s}^{-1}$, 138 after equilibrium for each shear rate. The oscillatory tests at $60{ }^{\circ} \mathrm{C}$ were carried out on a new 139 aliquot at $4 \%$ strain (linear viscoelastic range). The frequency range investigated was from 0.5 140 to $100 \mathrm{rad} / \mathrm{s}$.

\section{4. Results and discussion}

\section{4.1. Granule size distribution}

144 The size distribution of starch granules was carried out before (Figure 1a) and after pasting

145 (Figure 1b) in the Brabender Viscograph. Table 1 presents the variation of the median diameter $146 \mathrm{D}_{\mathrm{V}, 0.5}$, the swelling ratio $\left(\mathrm{D} / \mathrm{D}_{0}\right)^{3}$ and the span, which measures the volume distribution width 147 of starch granules, for SMS, WMS, WTS and PTS.

148 Before pasting the native starches exhibit a narrow size distribution of the granules, the median 149 diameter lying between 12.9 for SMS, the smaller starch granules, to $44.6 \mu \mathrm{m}$ for PTS the 150 larger ones with also a minor peak at approximately one micron. These values correspond to 151 the usual starch granule size distribution. For DIC treated starches, the size distribution curves 152 before pasting were shifted towards higher sizes and broadened as increasing DIC conditions, 153 with large differences depending on botanical origin: SMS being more prone to swell than 154 WMS and WTS showing a dramatic increase at 3bar/5min. For PTS only slight modifications 
155 were observed due to the low intensity of the DIC conditions. A progressive increase of the

156 median diameter with the intensity of the treatment is attested for all starches. The span values 157 increased for SMS, WMS and WTS, after DIC treatment reflecting a widening of the granule 158 size distribution. This was particularly important for SMS (Table 1) and is probably due to the 159 presence of a third peak at approximately 200 microns (Figure 1) corresponding to aggregates 160 of starch granules. The different evolution of the swelling ratio $\left(\mathrm{D} / \mathrm{D}_{0}\right)^{3}$ clearly underlines the 161 differences between starches: SMS and WTS present the highest swelling capacities at $1623 \mathrm{bar} / 5 \mathrm{~min}$ of 105.7 and 327.6, respectively. Such a behaviour, particularly for WTS, reflects 163 the cold swelling of DIC treated starch granules; it is not mentioned in the literature for HMT

164 treated starches and has been ascribed to partial loss of cristallinity and subsequent enhanced 165 capacity to hydration (Loisel et al., 2006).

166 After pasting, the size distribution curves (Figure 1) of all the native starches exhibit a shift 167 towards larger sizes as expected. The 1bar/60min treated starches, SMS, WMS and WTS, 168 present the same distribution curve as the native ones with smoothing of the minor peak for 169 WMS. But the 2bar/60min and 3bar/5min treated SMS and WMS show the reverse tendency: a 170 shift towards a lower starch granules size. For SMS and WMS the minor peak at one micron 171 was converted into a larger one, at approximately $5 \mu \mathrm{m}$, which disappeared for the most severe 172 conditions for WMS. This peak may be attributed to a population of small starch granules that 173 swell upon pasting or to the disruption of larger ones. The median diameters $\mathrm{D}_{\mathrm{V}, 0.5}$ (Table 1) 174 increase for native starch after pasting as expected (from 12.9 to $41.1 \mu \mathrm{m}, 14.3$ to $32.5 \mu \mathrm{m}$, 17519.8 to $36.6 \mu \mathrm{m}$ and 44.6 to $112.3 \mu \mathrm{m}$ ) for SMS, WMS, WTS and PTS, respectively. The DIC 176 treated SMS and WMS starches present similar sizes to the native ones for the lowest DIC 177 conditions (1bar/60min). For medium and high DIC conditions a progressive decrease is 178 observed: the swelling ratio reaches 0.4 for SMS and WMS at 3bar/5min. This modification 179 can be ascribed to concomitant processes of swelling and disruption of starch granules 
180 encountered during the pasting process. For DIC treated SMS and WMS the disruption

181 phenomenon may prevail owing to the sensitivity of starch granules induced by the treatment.

182 WTS exhibited an outstanding behaviour, by increasing the size of starch granules for the most

183 severe condition (swelling ratio 1.93 for $3 \mathrm{bar} / 5 \mathrm{~min}$ ). These modifications of the starch granules

184 size distribution by DIC treatment will obviously affect the rheological properties.

\section{4.2. Rheological properties}

186 Figure 2 presents the rheograms of native and DIC treated starches of SMS, WMS, WTS and

187 PTS. The flow curves are typical of shear-thinning fluids, except the ones of samples treated at

188 2bar/60min and 3bar/5min for SMS, 3bar/5min for WTS and at $1.5 \mathrm{bar} / 5 \mathrm{~min}$ for PTS. We also

189 observe the persistence of the thixotropic behaviour of the starches, which may result from a

190 disruption of starch granules aggregates under shearing. This phenomenon appeared less

191 pronounced when the treatment conditions increased and disappeared for samples treated at

$1923 \mathrm{bar} / 5 \mathrm{~min}$ for SMS and 1.5bar/5min for PTS.

193 The Herschel-Bulkley equation (Eq.2) was applied satisfactorily from the equilibrium curves

194 (not presented in Figure 2) according to Eq. (2):

$195 \tau=\tau_{0}+k \gamma^{n}$

$196 \tau$ is the shear stress $(\mathrm{Pa}), \gamma$ is the shear rate $\left(\mathrm{s}^{-1}\right), \tau_{0}$ is the yield stress $(\mathrm{Pa}), \mathrm{K}$ is the 197 consistency index $\left(\mathrm{Pa}_{\mathrm{s}} \mathrm{s}^{\mathrm{n}}\right)$ and $\mathrm{n}$ is the flow behaviour index (dimensionless).

198 The values of the flow parameters $\left(\tau_{0}, \mathrm{~K}, \mathrm{n}\right)$ and the apparent viscosity for $1 \mathrm{~s}^{-1}$ are given in

199 Table 2. We observe shear-thinning behaviour $(n<1)$ with a yield stress for all the native and 200 treated starches except at 2bar/60min and 3bar/5min for SMS, 3bar/5min for WTS, and 201 1.5bar/5min for PTS. For these DIC conditions, the rheological behaviour of treated starches 202 tended towards a Newtonian one with increasing flow behaviour index. 
203 For WMS and WTS the flow behaviour index remains almost constant for all the process 204 conditions. For all starches the increase of the process conditions causes a decrease of the yield stress and of the apparent viscosity except for WTS.

In Table 2 are presented the values of the storage modulus (G'), and the loss modulus (G') measured at $60{ }^{\circ} \mathrm{C}$. The suspensions of native starches exhibited the behaviour of a weak gel with G'>G', and G' almost independent of frequency (mechanical spectra, not shown).

209 The storage modulus G' sharply decreased for SMS as the process conditions became more 210 intense, while the decrease was more progressive for WMS. This effect of the DIC process on 211 the viscoelasticity of SMS and WMS starch suspensions agrees with previous results (Loisel et

212 al., 2006). WTS is the only starch which behaved in a different way, exhibiting an increase of 213 the storage modulus with the processing conditions.

214 Considering the effect of the treatment on the global properties of the starch suspensions, we 215 can observe the same evolution between the rheological parameters (yield stress, viscosity, 216 storage modulus, Table 2) and the size of the starch granules after pasting (Table 1): a tendency 217 to a decrease for SMS, WMS and PTS and to an increase for WTS with the intensity of the 218 treatment. But no direct relationship can be drawn between these two characteristics as the 219 volume fraction of starch granules is not taken into account. It is well known that the 220 rheological behaviour of a pasted starch suspension is the result of two main characteristics: the 221 viscosity of the continuous phase and the volume fraction of the dispersed phase constituted by 222 the starch granules (Doublier et al., 1987). The concentrations of the starch suspensions used in 223 that study are very close to the packing concentration described by Steeneken (1989): i.e. the 224 suspension can be assimilated to a packing of swollen starch granules that are responsible for 225 the overall rheological properties of the suspensions, the contribution of the continuous phase 226 being minored. In such a concentrated system, the storage modulus indirectly measures the 227 rigidity of the swollen granules. The decrease of the storage modulus for SMS and WMS 
resulting from the intensity of the treatment may reflect either a loss of rigidity of starch 229 granules; or more probably a decrease of their volume fraction.

230 The DIC process presents some similarities with the HMT treatment as it is conducted at low 231 moisture content between 15 and $20 \%$ for DIC (depending on the pressure) compared to the $23230 \%$ usually used for HMT. All the authors state a decrease of the swelling factor (generally 233 expressed as the volume of swollen granules to the volume of the dry starch) and of the 234 Brabender viscosity after pasting and for SMS (Chung et al., 2009) and in a lesser extent for 235 WMS (Hoover and Manuel, 1996; Gunaratne and Corke, 2007). PTS presents the greatest 236 sensitivity to the HMT treatment according to these two characteristics (Gunaratne and Hoover, 237 2002) while WTS exhibits a decrease of the swelling factor but a minor viscosity loss 238 (Gunaratne and Corke, 2007) or even a slight increase of the viscosity after pasting (Hoover 239 and Vasanthan, 1994). The effect of the DIC treatment on the rheological properties of starch 240 suspensions seems similar to a certain extent to the one of HMT treatment.

\section{5. Conclusion}

242 This study has shown that the rheological and morphological properties of starches from 243 different botanical origins, standard maize (SMS), waxy maize (WMS), wheat (WTS) and 244 potato (PTS), are influenced to a different extent by the processing conditions applied during 245 the DIC treatment. The PTS is more sensitive to the treatment than other starches, whereas 246 WMS and WTS are more resistant. When the processing treatments are intense the size 247 distributions of the starch granules and the rheological properties of starch suspensions vary.

248 We observed a reduction in swelling for SMS and WMS starch granules after pasting which 249 was ascribed to their prevailing disruption. For WTS the reverse result was observed. The 250 rheological behaviour tends to Newtonian behaviour $(n=1)$, except for WMS, with a decrease 251 of the yield stress and the apparent viscosity as the processing conditions increase. The 
252 rheological properties are related to the evolution of the size of starch granules with the DIC 253 treatment. 
255 Barron, C., Buléon, A., Colonna, P., \& Della Valle, G. (2000). Structural modifications of low 256 hydrated pea starch subjected to high thermomechanical processing. Carbohydrate Polymers, $257 \quad 43,171-181$.

258 Collado, L. S., \& Corke, H. (1999). Heat-moisture treatment effects on sweet potato starches 259 differing in amylose content. Food Chemistry, 65, 329-346.

260 Chung, H.J., Hoover, R., \& Liu, Q. (2009). The impact of single and dual hydrothermal 261 modifications on the molecular structure and physicochemical properties of normal corn 262 starch. International Journal of Biological Macromolecules, 44, 203-210.

263 Donovan, J.W., Lorenz K., \& Kulp K. (1983). Differential scanning calorimetry of heat 264 moisture treated wheat and potato starches. Cereal Chemistry, 60, 381-387.

265 Doublier, J.L., Llamas, G., \& Le Meur, M. (1987). A rheological investigation of cereal starch 266 pastes and gels. Effect of pasting procedures. Carbohydrate Polymers, 7, 251-275.

267 Gunaratne, A., \& Corke, H. (2007). Effect of hydroxypropylation and alkaline treatment in 268 hydroxypropylation on some structural and physicochemical properties of heat-moisture 269 trated wheat, potato and waxy maize starches. Carbohydrate Polymers, 68, 305-313.

270 Gunaratne, A., \& Hoover, R. (2002). Effect of heat-moisture treatment on the structure and 271 physical properties of tuber and root starches. Carbohydrate Polymers, 49, 425-437. 
272 Hoover, R., \& Manuel. H. (1996). Effect of heat-moisture treatment on the structure and 273 physicochemical properties of normal maize, waxy maize, dull waxy maize and amylomaize 274 V starches. Journal of Cereal Science, 23, 153-162.

275 Hublin, L. (1994). Influence des caractéristiques structurales des amidons natifs sur leur 276 réactivité chimique. $\mathrm{PhD}$ dissertation, Université de Nantes. France.

277 Jacobs, H., Mischenko, N., Koch, M. H. J., Eerlingen, R. C, Delcour. J. A., \& Reynaers, H. 278 (1998). Evaluation of the impact of annealing on gelatinisation at intermediate water content 279 of wheat and potato starches: A differential scanning calorimetry and small angle X-ray 280 scattering study. Carbohydrate Research, 306, 1-10.

281 Jayakody, L., \& Hoover, R. (2008). Effect of annealing on the molecular structure and 282 physicochemical properties of starches from different botanical origins - A review. 283 Carbohydrate Polymers, 74, 691-703.

284 Karlsson, M.E., \& Eliasson, A.-C. (2003). Gelatinization and retrogradation of potato 285 (Solanum tuberosum) starch in situ as assessed by differential scanning calorimetry (DSC) 286 Lebensmittel-Wissenschaft und-Technologie/FST, 36 (8), 735-741.

287 Kulp, K., \& Lorenz, K. (1981). Heat-moisture treatment of starches. I- Physicochemical 288 properties. Cereal Chemistry, 58, 46-48.

289 Lawal, O.S. (2005). Studies on the hydrothermal modifications of new cocoyam (Xanthosoma 290 sagittifolium) starch. International Journal of Biological Macromolecules, 37 (5), 268-277.

291 Lim, S. T., Chang, E. H., \& Chung, H. J. (2001). Thermal transition characteristics of heatmoisture treated corn and potato starches. Carbohydrate Polymers, 46, 107-115. 
293 Loisel, C., Maache-Rezzoug, Z., Esneault, C., \& Doublier, J. L. (2006). Effect of 294 hydrothermal treatment on the physical and rheological properties of maize starches. Journal 295 of Food Engineering, 73, 45-54.

296 Maache-Rezzoug, Z., Zarguili, I., Loisel, C., Queveau, D., \& Buléon, A. (2008). Structural 297 modifications and thermal transitions of standard maize starch after DIC hydrothermal 298 treatment. Carbohydrate Polymers, 74, 802-812.

299 Maache-Rezzoug, Z., \& Allaf, K. (2005). Study of the effect of hydrothermal process 300 conditions on pasta quality. Journal of Cereal Science, 41, 267-275.

301 Maruta, I., Kurahashi, Y., Takayano, R., Hayashi, K., Yoshino, Z., Komaki, T., \& Hara, S. 302 (1994). Reduced-pressurized heat-moisture treatment. A new method for heat-moisture 303 treatment of starch. Starch/Stärke, 46, 177-181.

304 Nayouf, M., Loisel, C., \& Doublier, J.L. (2003). Effect of thermomechanical treatment on the 305 rheological properties of crosslinked waxy corn starch. Journal of Food Engineering, 59, 209306219.

307 Rezzoug, S.A., Maache-Rezzoug, Z., Mazoyer, J., Jeannin, M., \& Allaf, K. (2000). Effect of 308 instantaneous controlled pressure drop proccess on hydration capacity of scleroglucan. 309 Optimisation of operating conditions by response surface methodology. Carbohydrate 310 Polymers, 42, 73-84.

311 Steeneken, P.A.M. (1989). Rheological properties of aqueous suspensions of swollen starch 312 granules. Carbohydrate Polymers, 11, 23-42. 
313 Tester, R. F., Debon, S. J. J., \& Sommerville, M. D. (2000). Annealing of maize starch.

314 Carbohydrate Polymers, 42, 287-299.

315 Tukomane, T., Leerapongnum, P., Shobsngob, S., \& Varavinit, S. (2007). Preparation and 316 characterization of annealed-enzymatically hydrolyzed tapioca starch and the utilization in 317 tableting. Starch/Stärke, 59(1), 33-45.

318 Vallous, N. A, Gavrielidou, M.A., Karapantsios, T.D., \& Kostoglou, M. (2002). Performance 319 of a double drum dryer for producing pregelatinized maize starches. Journal of Food 320 Engineering, 51, 171-183.

321 Vermeylen, R., Goderis, B., \& Delcour, J. A. (2006). An X-ray study of hydrothermally treated 322 potato starch. Carbohydrate Polymers, 64, 364-375.

323 Zarguili, I. (2006). Etude de l'effet de l'hydrotraitement DIC sur les propriétés structurales et 324 fonctionnelles des amidons de différentes origines botaniques. PhD dissertation, University of 325 La Rochelle. France

326 Zarguili, I., Maache-Rezzoug, Z., Loisel, \& C., Doublier, J.-L. (2006). Influence of DIC 327 hydrothermal process conditions on the gelatinization properties of standard maize starch. 328 Journal of Food Engineering, 77 (3), 454-461.

329 Zarguili, I., Maache-Rezzoug, Z., Loisel, C., \& Doublier, J.-L. (2009. A mathematical model 330 to describe the change of moisture distribution in maize starch during DIC hydrothermal 331 treatment. International Journal of Food Science and Technology, 44, 10-17. 
335 Figure 1: Size distribution of native and DIC treated SMS, WMS, WTS, and PTS starches: (a) 336 before pasting and (b) after pasting.

337

338 Figure 2: Flow curves of native and DIC treated starch dispersions measured at $60{ }^{\circ} \mathrm{C}$ after 339 pasting, with starch concentration of $6 \%, 4 \%, 7 \%$ and $2 \%$ for SMS, WMS, WTS and PTS, 340 respectively. 
Figure 1

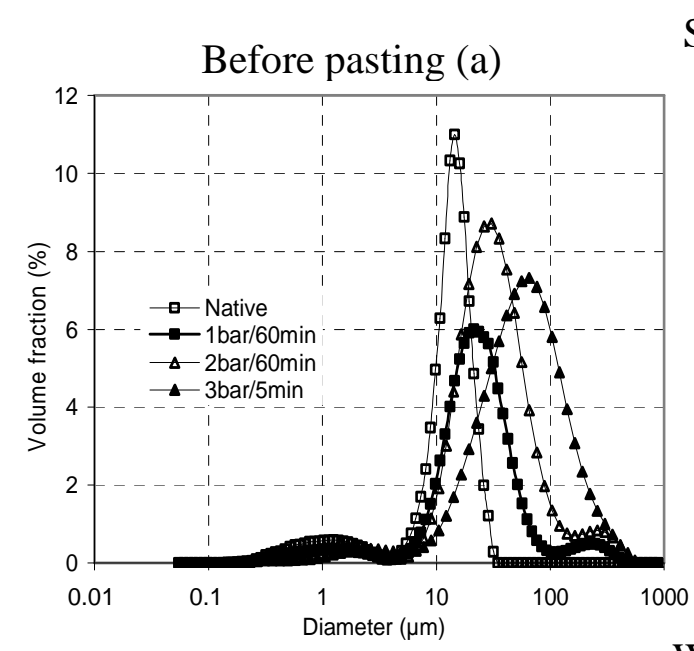

SMS After pasting (b)
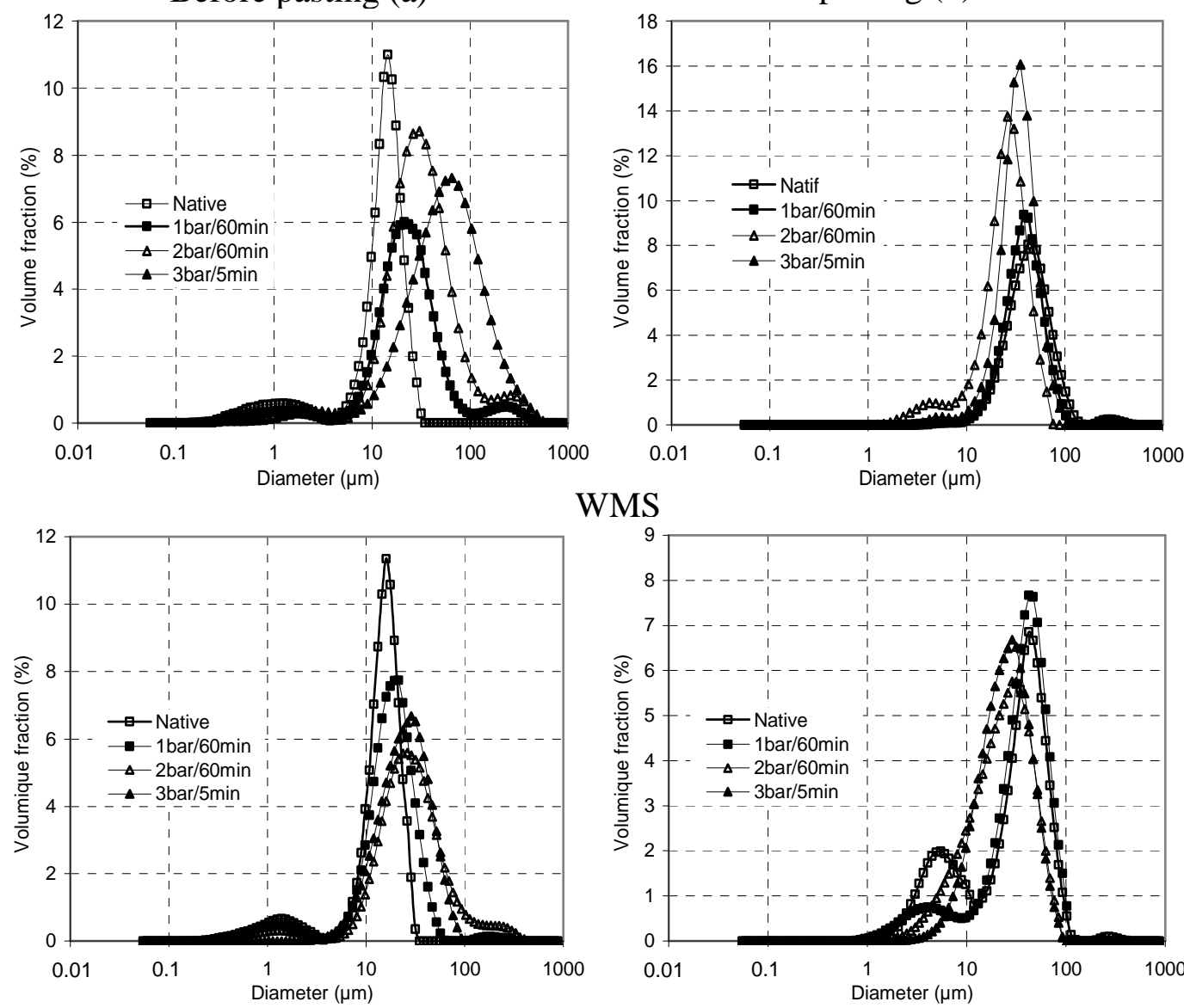

WMS

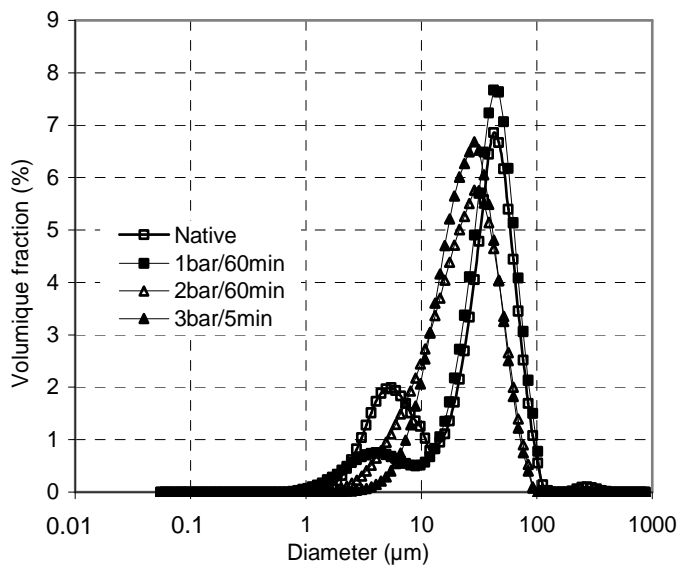

WTS
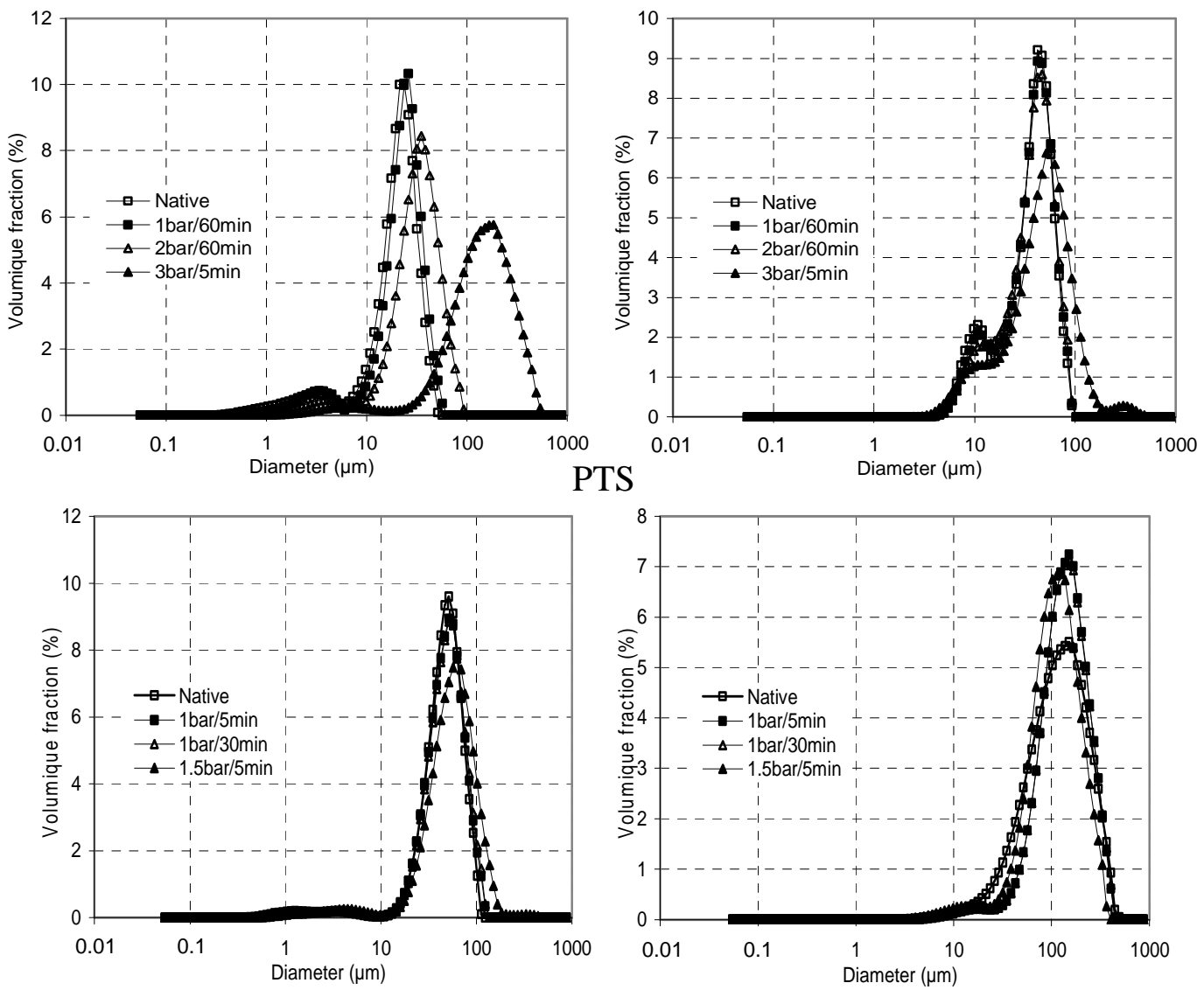

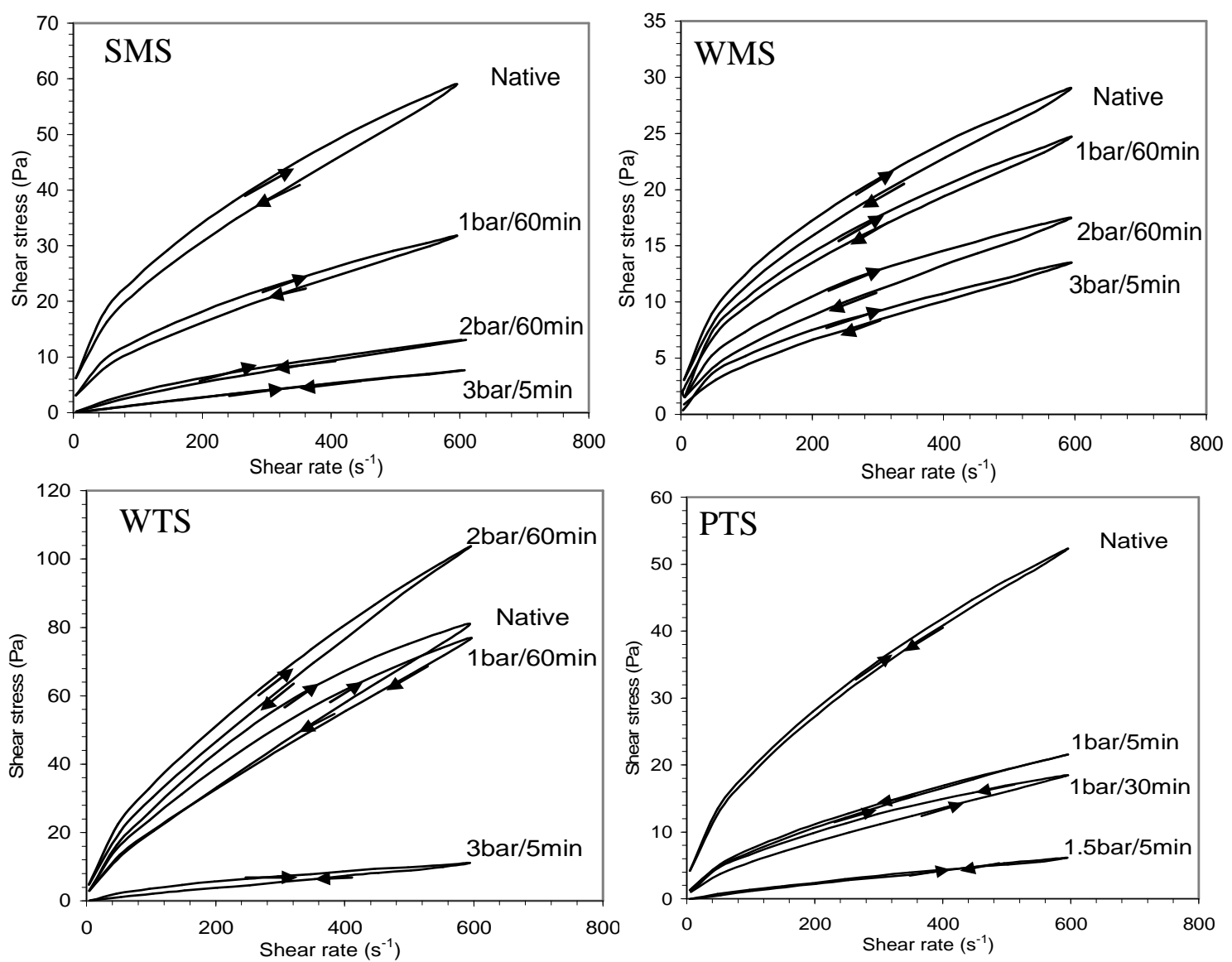
344 Table 1: Particle size characteristics of SMS, WMS, WTS and PTS after DIC treatment.

345 (standard deviation of $\mathrm{Dv}, 0.5=0.3 \mu \mathrm{m}$ )

346

\begin{tabular}{|c|c|c|c|c|c|c|c|}
\hline \multirow[b]{3}{*}{$\begin{array}{l}\text { Starch } \\
\text { source }\end{array}$} & \multirow{3}{*}{$\begin{array}{l}\text { DIC conditions } \\
\text { Pressure level/ } \\
\text { processing time } \\
\text { (bar/min) }\end{array}$} & \multicolumn{6}{|c|}{ Granulometry } \\
\hline & & \multicolumn{3}{|c|}{ Before pasting } & \multicolumn{3}{|c|}{ After pasting } \\
\hline & & $\begin{array}{l}D_{V, 0.5} \\
(\mu \mathrm{m})\end{array}$ & $\left(\mathrm{D} / \mathrm{D}_{\mathrm{o}}\right)^{3}$ & Span & $\begin{array}{c}D_{V, 0.5} \\
(\mu \mathrm{m})\end{array}$ & $\left(\mathrm{D} / \mathrm{D}_{\mathrm{o}}\right)^{3}$ & Span \\
\hline \multirow[t]{4}{*}{ SMS } & native & 12.9 & 1.0 & 1.4 & 41.1 & 1.0 & 1.3 \\
\hline & $1 / 60$ & 19.3 & 3.3 & 1.5 & 39.3 & 0.9 & 1.2 \\
\hline & $2 / 60$ & 27.7 & 9.9 & 2.4 & 23.8 & 0.2 & 1.3 \\
\hline & $3 / 5$ & 61.0 & 105.7 & 2.5 & 29.6 & 0.4 & 1.8 \\
\hline \multirow[t]{4}{*}{ WMS } & native & 14.3 & 1.0 & 1.1 & 32.5 & 1.0 & 1.8 \\
\hline & $1 / 60$ & 17.1 & 1.2 & 1.4 & 36.1 & 1.4 & 1.7 \\
\hline & $2 / 60$ & 25.3 & 5.5 & 2.4 & 22.5 & 0.3 & 1.8 \\
\hline & $3 / 5$ & 39.5 & 21.1 & 1.8 & 23.7 & 0.4 & 1.5 \\
\hline \multirow[t]{4}{*}{ WTS } & native & 19.8 & 1.0 & 1.2 & 36.6 & 1.0 & 1.3 \\
\hline & $1 / 60$ & 22.2 & 1.4 & 1.2 & 36.8 & 1.0 & 1.3 \\
\hline & $2 / 60$ & 30.5 & 3.6 & 1.4 & 36.7 & 1.0 & 1.4 \\
\hline & $3 / 5$ & 136.5 & 327.6 & 1.8 & 45.6 & 1.9 & 1.8 \\
\hline \multirow[t]{4}{*}{ PTS } & native & 44.6 & 1.0 & 1.2 & 112.3 & 1.0 & 1.9 \\
\hline & $1 / 5$ & 45.8 & 1.1 & 1.2 & 114.8 & 1.1 & 1.5 \\
\hline & $1 / 30$ & 46.4 & 1.1 & 1.2 & 114.4 & 1.1 & 1.5 \\
\hline & $1.5 / 5$ & 54.1 & 1.8 & 1.4 & 104.9 & 0.8 & 1.5 \\
\hline
\end{tabular}


347 Table 2: Herschel-Bulkley parameters and viscoelastic properties of SMS, WMS, WTS and 348 PTS pasted suspensions after DIC treatment.

\begin{tabular}{|c|c|c|c|c|c|c|c|c|}
\hline & \multicolumn{2}{|l|}{ DIC conditions } & \multicolumn{3}{|c|}{$\begin{array}{c}\text { Flow behaviour } \\
60^{\circ} \mathrm{C} \\
\end{array}$} & \multicolumn{3}{|c|}{$\begin{array}{c}\text { Viscoelasticity } \\
\left(60^{\circ} \mathrm{C} ; 6.3 \mathrm{rad} / \mathrm{s}\right)\end{array}$} \\
\hline Starch source & $\begin{array}{l}\text { Pressure level / } \\
\text { processing time } \\
\text { (bar / min) }\end{array}$ & $\begin{array}{l}\tau_{\mathrm{o}} \\
(\mathrm{Pa})\end{array}$ & $\begin{array}{l}\mathrm{K} \\
\left(\operatorname{Pa} \mathrm{s}^{\mathrm{n}}\right)\end{array}$ & $\mathrm{n}$ & $\begin{array}{l}\eta_{\mathrm{a}} \\
\text { (Pa.s) }\end{array}$ & $\begin{array}{l}\mathrm{G}^{\prime} \\
(\mathrm{Pa})\end{array}$ & $\begin{array}{l}\text { G" } \\
(\mathrm{Pa})\end{array}$ & $\operatorname{Tan}(\delta)$ \\
\hline \multirow[t]{4}{*}{$\mathrm{SMS}^{\mathrm{a}}$} & native & 2.28 & 1.39 & 0.57 & 3.68 & 126.7 & 16.6 & 0.13 \\
\hline & $1 / 60$ & 0.68 & 0.72 & 0.58 & 1.41 & 115.4 & 13.4 & 0.12 \\
\hline & $2 / 60$ & 0.00 & 0.04 & 0.91 & 0.04 & 0.43 & 0.16 & 0.37 \\
\hline & $3 / 5$ & 0.00 & 0.01 & 1.00 & 0.01 & 3.12 & 0.91 & 0.29 \\
\hline \multirow[t]{4}{*}{$\mathrm{WMS}^{\mathrm{b}}$} & native & 0.70 & 0.88 & 0.53 & 1.58 & 1.96 & 1.06 & 0.54 \\
\hline & $1 / 60$ & 0.71 & 0.81 & 0.52 & 1.52 & 1.69 & 0.93 & 0.55 \\
\hline & $2 / 60$ & 0.31 & 0.26 & 0.62 & 0.57 & 1.12 & 0.74 & 0.66 \\
\hline & $3 / 5$ & 0.36 & 0.58 & 0.54 & 0.95 & 1.20 & 0.90 & 0.75 \\
\hline \multirow[t]{4}{*}{$\mathrm{WTS}^{\mathrm{c}}$} & native & 0.95 & 0.44 & 0.78 & 1.39 & 21.7 & 11.2 & 0.52 \\
\hline & $1 / 60$ & 0.87 & 0.75 & 0.70 & 1.63 & 30.1 & 12.8 & 0.45 \\
\hline & $2 / 60$ & 1.00 & 0.87 & 0.72 & 1.87 & 26.9 & 10.5 & 0.39 \\
\hline & $3 / 5$ & 0.00 & 0.03 & 0.88 & 0.03 & 63.5 & 12.4 & 0.19 \\
\hline \multirow[t]{4}{*}{$\mathrm{PTS}^{\mathrm{d}}$} & native & 0.77 & 1.28 & 0.57 & 2.05 & 9.70 & 6.4 & 0.66 \\
\hline & $1 / 5$ & 0.06 & 0.47 & 0.60 & 0.53 & 3.90 & 2.5 & 0.64 \\
\hline & $1 / 30$ & 0.02 & 0.15 & 0.71 & 0.17 & 4.10 & 2.7 & 0.66 \\
\hline & $1.5 / 5$ & 0.00 & 0.02 & 0.89 & 0.02 & 0.34 & 0.04 & 0.11 \\
\hline
\end{tabular}

